\title{
Análise microscópica de concreto pigmentado com resíduos de borracha aplicado em piso intertravado
}

\author{
Microscopic analysis of pigmented concrete \\ with rubber waste applied to the interlocking \\ block
}

\author{
Betolvem Cristhian Lucio da Silva ${ }^{1}$, Luisa Andreia Gachet ${ }^{1}$, \\ Rosa Cristina Cecche Lintz ${ }^{1}$
}

\footnotetext{
${ }^{1}$ Faculdade de Tecnologia, Universidade Estadual de Campinas, Rua Paschoal Marmo, 1888, CEP: 13484-332, Jardim Nova Itália, Limeira, SP, Brasil.

e-mail: betolvem@gmail.com, gachet@ft.unicamp.br, rosacclintz@ft.unicamp.br
}

\begin{abstract}
RESUMO
Neste trabalho foi analisada a microestrutura do concreto pigmentado com e sem resíduos de borracha, por meio do microscópio eletrônico de varredura, visando sua aplicação na fabricação de pisos intertravados. Verificou-se que o concreto de referência (sem borracha) apresentou pasta densa e compacta e de acordo com o aumento do teor de borracha no concreto, observou-se a tendência da crescente porosidade e número de vazios na pasta de cimento, aparecimento de microfissuras e zona de transição acentuada entre os agregados e a pasta, com exceção para o traço contendo 5\% de borracha. Estas análises possibilitaram um melhor entendimento do comportamento mecânico desses concretos. O aglomerante empregado foi o cimento Portland branco estrutural. Objetivando atribuir ao piso intertravado mais uma vantagem arquitetônica e estética empregou-se um pigmento do tipo inorgânico a base de óxidos de ferro e cromo de tonalidade azul. O resíduo de borracha utilizado em substituição parcial ao agregado miúdo (areia natural) foi proveniente do processo de recauchutagem de pneus, e adicionado ao concreto nas seguintes proporções 2,5\%, 5,0\%, 10\%, 20\%, 30\% enquanto o teor de pigmento foi mantido constante, sendo $6 \%$ em relação à massa de cimento. Com relação aos ensaios mecânicos, os resultados indicaram que, para os traços contendo $2,5 \%$ e 5,0\% de resíduos de borracha a norma ABNT NBR 9781:2013 é atendida com relação à resistência característica à compressão aos 28 dias (maior ou igual a $35 \mathrm{MPa}$ ), fato que não aconteceu para os traços com 10\%, 20\%, 30\%. Considerando as composições do concreto estudadas nesta pesquisa, pode-se afirmar que o emprego de resíduos de borracha como substituto parcial da areia é uma alternativa de reciclagem do produto que agregada muito ao meio ambiente e evita o descarte inadequado deste passivo ambiental.
\end{abstract}

Palavras-chave: Materiais Alternativos. Microestrutura. Piso Intertravado. Borracha.

\begin{abstract}
In this work the microstructure of pigmented concrete with and without rubber residue was analyzed by scanning electron microscope, aiming its application in the manufacture of interlocking block. It was verified that the reference concrete (without rubber) presented dense and compact paste and according to the increase of the rubber content in the concrete, the tendency was observed to increase the porosity and number of voids in the cement paste, appearance of cracks and zone of sharp transition between aggregates and paste, except for the trace containing 5\% rubber. These analyzes allowed a better understanding of the mechanical behavior of these concretes. The binder employed was structural white Portland cement. In order to give the interlocking block another architectural and aesthetic advantage, an inorganic type pigment based on iron oxides and blue chrome was used. The rubber residue used as a partial replacement for fine aggregate (natural sand) came from the tire retreading process and was added to the concrete in the following proportions $2.5 \%, 5.0 \%, 10 \%, 20 \%, 30 \%$ while the pigment content was kept constant, being $6 \%$ in relation to the cement mass. Regarding the mechanical tests, the results indicated that, for the traces containing $2.5 \%$ and $5.0 \%$ of rubber residues, the ABNT NBR 9781:2013 standard is attended with respect to the characteristic
\end{abstract}


compressive strength at 28 days (greater than or equal to $35 \mathrm{MPa}$ ), which did not happen for the traces with $10 \%, 20 \%, 30 \%$. Considering the concrete compositions studied in this research, it can be stated that the use of rubber waste as a partial substitute for sand is an alternative for recycling the product which adds a lot to the environment and avoids the inappropriate disposal of this environmental liability.

Keywords: Alternative Materials. Microstructure. Interlocking Block. Rubber.

\section{INTRODUÇÃO}

O emprego de pavimentos intertravados vem crescendo aceleradamente nos centros urbanos, seja pela versatilidade quanto a facilidade de fabricação, assentamento e durabilidade.

Os pisos intertravados de concreto é um sistema de pavimentação que surgiu na Europa do pós-guerra e foi introduzido no Brasil na década de 1970. As diversas possibilidades de cores e formatos viabilizam o assentamento deste tipo de pavimento em: praças, parques, jardins, calçadas, estacionamentos, vias urbanas, pátios, depósitos, galpões, indústrias e rodovias (FIORITI et al. [1]).

Segundo JAMSHIDI et al. [2], no Japão, o pavimento intertravado de blocos de concreto tem tido grande aceitação social pelo seu desempenho técnico sendo considerado um material sustentável e indicado como um dos pavimentos do futuro para as próximas gerações. Os pavimentos intertravados são construídos com blocos pré-fabricados de concreto, maciços, que permitem pavimentar uma superfície completa. O intertravamento é a capacidade que as peças adquirem de resistirem a movimentos de deslocamento individual, seja ele vertical, horizontal, de rotação ou de giração em relação as peças adjacentes (FIORITI et al. [1]).

Existem três métodos comumente empregados na produção dos pisos intertravados de concreto: compactação manual, compactação em máquina, métodos de alta frequência de vibração e compactação. Segundo LING [3] destes três métodos citados, o terceiro é totalmente automatizado, rápido e eficiente conferindo ao material maior densidade, melhor resistência, menor permeabilidade e menor estrutura de poros. LING [3] verificou o aumento da resistência à compressão de pisos de concreto com 10\% de resíduos de borracha produzidos em misturadores de alta frequência. O pesquisador atribui este valor a um empacotamento ótimo das partículas, a redução da porosidade e a perfeita aderência entre a matriz de borracha e cimento verificada nas imagens da microestrutura do material. LING [3] também observou que os pisos com borracha são capazes de absorver maiores quantidades de energia aumentando a ductilidade do concreto.

No Brasil os pisos de concreto são produzidos em larga escala em vibro prensas multifuncionais ou em menor escala em misturadores do tipo betoneira. Na sua composição geralmente são empregados cimento Portland, agregados graúdo e miúdo, aditivo, água, e eventualmente pigmentos.

Materiais como cimento Portland branco estrutural, agregados coloridos e pigmentos permitem a moldagem de pisos de concreto com diferentes colorações atribuindo ao material mais uma vantagem arquitetônica e estética.

Na composição do concreto destes pisos também é possível incorporar agregados reciclados e/ou resíduos sólidos em substituição parcial aos agregados naturais. A borracha de pneus é um dos materiais que têm sido largamente empregada na fabricação de concretos. Alguns estudos mostram que a utilização deste tipo de resíduo em concretos tem trazido benefícios ao meio ambiente (SOFI [4]; SILVA et al. [5]; GERGES et al. [6]; WANG et al. [7]), além de melhoria de algumas propriedades mecânicas, tais como: aumento da ductilidade, da capacidade de absorção de energia, da tenacidade (LI et al. [8]), da energia de fratura (BIDECI et al. [9]; LI et al. [8]), de propriedades dinâmicas (ZHENG et al. [10]; NAJIM E HALL [11]) e da resistência ao impacto (ABDELALEEM et al. [12]).

SILVA et al. [13] obtiveram perdas na resistência à compressão de concretos com adição de $6 \%$ e $9 \%$ de resíduos de borracha, de $15 \%$ e $17 \%$ respectivamente.

PELISSER et al. [14] observaram que a presença de sílica ativa nas misturas de concreto com borracha tratada com hidróxido de sódio favoreceu a redução da porosidade na interface entre os agregados e a pasta de cimento, contribuindo para melhor adesão e redução dos pontos fracos no material endurecido.

SILVA et al. [15] ao estudarem o comportamento de piso tátil de concreto com borracha verificaram que: (a) quanto a consistência do concreto, quanto maior o teor de borracha na mistura, menor o valor do abatimento; (b) quanto a resistência à compressão, para misturas com até $10 \%$ de substituição da areia pela borracha, há aumento desta propriedade em relação ao traço de referência; para teores maiores de substituição, de $10 \%$ a $50 \%$ há a diminuição da resistência à compressão em relação ao traço de referência, porém os valores atendem as especificações da norma brasileira para piso; (c) quanto a resistência à tração na flexão, para o concreto com $50 \%$ de borracha, aos 28 dias, há diminuição desta propriedade de aproximadamente $32 \%$, em relação ao traço de referência; (d) a borracha de pneu melhora significativamente a resistência à 
abrasão do concreto.

AGUIAR [16] estudou a influência do teor de adição de pigmentos na resistência à compressão de concretos de cimento Portland branco e verificou que, com o aumento da porcentagem de pigmento, há queda da trabalhabilidade no estado fresco e diminuição da resistência à compressão em relação a concretos sem pigmento. Verificou também que, ao empregar no concreto teores de pigmento de 3\%, 6\% e 9\% em relação a massa de cimento, os pigmentos de tonalidades amarelo e vermelho apresentam valores de resistência à compressão maior para concretos com $6 \%$ de pigmento comparando-se com concretos contendo $3 \%$ de pigmento.

LEE et al. [17] sugerem relação pigmento-cimento abaixo de 4\%, quando os pigmentos a base de óxido de ferro são empregados em pisos intertravados de concreto.

PIOVESAN [18] estudou o efeito da adição de pigmento em algumas propriedades de durabilidade, resistência à compressão e na cromacidade de concretos de cimento Portland branco. Verificou que a adição de $6 \%$ de pigmento vermelho, a base de óxido de ferro, e $10 \%$ do pigmento verde, a base de óxido de cromo, majoram a resistência à compressão e algumas propriedades de durabilidade do concreto principalmente para elevadas relações a/c. A pesquisadora atribui este fato ao efeito físico apresentado pelo pigmento que, devido a sua alta finura, promove um melhor empacotamento e maior dispersão na mistura de concreto. Quanto à cromacidade, PIOVESAN [18] observou que o emprego de $6 \%$ de pigmento vermelho no concreto, este atinge tonalidades próximas a cor original do pigmento, ao passo que para os concretos com pigmento verde é necessária a adição de $10 \%$ para se obter tonalidades mais escuras e mais próximas a cor do pigmento.

É justamente dentro deste contexto que se optou em estudar a incorporação no concreto, de $6 \%$ de pigmento em relação a massa de cimento, para garantir que a tonalidade das peças de concreto fosse próxima a cor original do pigmento.

O emprego de cimento Portland branco estrutural na produção das peças de concreto permite atender ao requisito quanto as propriedades mecânicas segundo a ABNT NBR 9781 [19], como arquitetônico em termos de cromacidade. No Brasil, o Cimento Portland Branco é regulamentado pela ABNT NBR 16697 [20], sendo classificado em dois subtipos: cimento Portland branco estrutural e cimento Portland branco não estrutural. Este material possui coloração branca, pois provém de matérias-primas com baixos teores de óxido de ferro e manganês e possui condições especiais de fabricação, principalmente durante o resfriamento e a moagem do produto.

Esta pesquisa trata da verificação da viabilidade técnica de peças de concreto destinadas a pisos intertravados de concreto, fabricadas com cimento Portland branco estrutural, $6 \%$ de pigmento e resíduos de borracha conforme a norma ABNT NBR 9781 [19].

\section{MATERIAIS E MÉTODOS}

Nesta pesquisa foram produzidos pisos intertravados de concreto contendo diferentes teores de resíduos de borracha, e seus resultados comparados com pisos intertravados de concreto sem adição de resíduos de borracha, denominados de pisos de referência. Os pisos foram submetidos a ensaios para a determinação da resistência à compressão, absorção de água e análise da microestrutura. Os resultados foram validados pela comparação com outros encontrados na literatura.

\subsection{Materiais}

Os materiais empregados nesta pesquisa foram: cimento Portland branco, agregado miúdo (areia natural e pó de pedra), agregado graúdo, resíduos de borracha, pigmento inorgânico na tonalidade azul, aditivo e água.

\subsubsection{Cimento portland branco (cpb)}

Nesta pesquisa foi empregado o cimento Portland branco estrutural de classe de resistência 40. Conforme a ABNT NBR 23 [21] a massa específica do cimento é igual a 3,03 g/ $\mathrm{cm}^{3} \mathrm{e}$, de acordo com a ABNT NBR 11579 [22], o índice de finura do cimento é igual a 0,35\%.

\subsubsection{Agregados}

Agregado miúdo: areia natural, de origem quartzosa, com massa específica de $2,64 \mathrm{~g} / \mathrm{cm}^{3}$ (ABNT NBR NM 52 [23]), massa unitária de $1,56 \mathrm{~g} / \mathrm{cm}^{3}$ (ABNT NBR 45 [24]), absorção de água de 0,10\% (ABNT NBR NM 30 [25]), módulo de finura de 1,64 e dimensão máxima característica 1,2 mm (ABNT NBR NM248 [26]). O 
pó de pedra possui massa específica de $2,94 \mathrm{~g} / \mathrm{cm}^{3}$ e absorção de água de 2,05\%, massa unitária de $1,58 \mathrm{~g} / \mathrm{cm}^{3}$, módulo de finura de 2,58 e dimensão máxima característica de 4,8 mm.

Agregado graúdo: agregado de origem basáltica, com massa específica de $3,00 \mathrm{~g} / \mathrm{cm}^{3}$ e absorção de água de 1,05\% (ABNT NBR NM 53 [27]), massa unitária de 1,56 g/cm³ (ABNT NBR NM 45[24]), módulo de finura de 5,79 e dimensão máxima característica de 9,5 mm (ABNT NBR NM248 [26]).

Resíduos de borracha: provenientes do processo de recauchutagem de pneus, possui massa específica de $1,15 \mathrm{~g} / \mathrm{cm}^{3}$ (ABNT NBR NM 52 [23] adaptada), massa unitária de 0,39 g/ $\mathrm{cm}^{3}$ (ABNT NBR 45 [24]), módulo de finura de 2,82 e dimensão máxima característica de 2,40 mm (ABNT NBR NM248 [26]). O resíduo de borracha utilizado foi aquele de passou pela peneira de abertura $2,4 \mathrm{~mm}$ e ficou retido na peneira de abertura $1,2 \mathrm{~mm}$.

\subsubsection{Aditivo}

O aditivo empregado é do tipo plastificante, multifuncional, a base de éter policarboxilato, com massa específica de $1,08 \mathrm{~g} / \mathrm{cm}^{3}$, estado líquido e cor marrom.

\subsection{4 Água}

A água usada foi proveniente do sistema de abastecimento urbano local.

\subsubsection{Pigmento}

O pigmento empregado foi do tipo inorgânico a base de óxidos de ferro e cromo de tonalidade azul. Nesta pesquisa foi empregado no concreto $6 \%$ de pigmento em relação à massa de cimento. Definiu-se por esta porcentagem afim de garantir a cor original do pigmento nas peças de concreto, uma vez que ainda não há um consenso entre os pesquisadores sobre o teor ideal (AGUIAR [16]; PIOVESAN [18]). Segundo o fabricante, este pigmento possui excelente resistência à luz, estabilidade em intempéries e resistência química.

Conforme a ABNT NBR 9781[19] os pigmentos empregados na fabricação de peças de concreto devem ser de base inorgânica.

\subsection{Produção dos pisos intertravados de concreto}

Para a produção dos pisos intertravados de concreto foi desenvolvido um traço de referência baseado nos estudos de Fernandes [28] e SILVA et al. [15]. O traço de referência, em massa, denominado de T0 foi igual a $1: 0,77: 2,33: 1,11: 0,01: 0,48: 0,06$ (cimento : areia : pó de pedra : brita $0: \mathrm{SP}: \mathrm{a}$ /c: pigmento). A partir do traço de referência foram calculados outros traços apresentados na Tabela 1. O resíduo de borracha substituiu parcialmente a massa de areia nas proporções: $2,5 \%, 5 \%, 10 \%, 20 \%$ e $30 \%$.

Tabela 1: Traço em massa dos concretos para a produção dos pisos intertravados.

\begin{tabular}{l|c|c|c|c|c|c}
\hline MATERIAIS & T0 & T2,5 & T5 & T10 & T20 & T30 \\
\hline Cimento CPB40 & 1 & 1 & 1 & 1 & 1 & 1 \\
\hline Pigmento inorgânico & 0 & 0,06 & 0,06 & 0,06 & 0,06 & 0,06 \\
\hline Agregado miúdo - areia & 0,77 & 0,75 & 0,73 & 0,69 & 0,61 & 0,54 \\
\hline Agregado miúdo - Pó de Pedra & 2,33 & 2,33 & 2,33 & 2,33 & 2,33 & 2,33 \\
\hline Agregado graúdo - Brita 0 & 1,11 & 1,11 & 1,11 & 1,11 & 1,11 & 1,11 \\
\hline Aditivo plastificante & 0,01 & 0,01 & 0,01 & 0,01 & 0,01 & 0,01 \\
\hline Água & 0,48 & 0,48 & 0,48 & 0,48 & 0,48 & 0,48 \\
\hline Resíduo de Borracha & 0 & 0,008 & 0,0167 & 0,033 & 0,066 & 0,10 \\
\hline
\end{tabular}

Foram moldados corpos de prova retangulares de pisos de concreto de dimensões 200x100x60 mm, segundo as especificações da ABNT NBR 9781 [19]. Os materiais, para a produção do concreto, foram misturados em betoneira de eixo inclinado, na seguinte ordem: parte da água, agregado graúdo, cimento, pigmento, agregados miúdos, resíduos de borracha. E, finalmente aditivo e o restante da água gradativamente até atingir a consistência ideal. 
A consistência dos concretos foi medida segundo o ensaio de abatimento pelo tronco de cone de acordo com a ABNT NBR 67 [29] sendo obtido abatimento de $5 \mathrm{~mm}$ para o traço de referência (T0) e, próximo a zero para as demais misturas. Dessa forma, os corpos de prova de pisos de concreto foram adensados em mesa vibratória e curados em câmara úmida até a data dos ensaios.

\subsection{Caracterização dos pisos intertravados conforme a ABNT NBR 9781:2013}

Segundo a norma brasileira ABNT NBR 9781 [19] a resistência característica à compressão, aos 28 dias, dos pisos destinados a tráfego de pedestres, veículos leves e veículos comerciais de linha deve ser fpk $\geq 35 \mathrm{MPa} \mathrm{e}$ fpk $\geq 50 \mathrm{MPa}$ para tráfego de veículos especiais. A absorção de água dos pisos de concreto deve ser $\leq 6 \%$.

\subsubsection{Determinação da massa específica e do teor de ar pelo método gravimétrico.}

Realizou-se uma única vez, no estado fresco do concreto, o ensaio para a determinação da massa específica, do rendimento e do teor de ar pelo método gravimétrico segundo a ABNT NBR 9833:2009 [30], logo após a etapa da mistura.

Segundo a NBR 9833:2009 [30] a massa específica aparente do concreto, deve ter aproximação de 1 $\mathrm{kg} / \mathrm{m}^{3}$ e o teor de ar deve ter aproximação de $0,1 \%$. A balança utilizada é eletrônica com capacidade de $51 \mathrm{~kg}$, precisão de $1 \mathrm{~g}$.

\subsubsection{Resistência à Compressão}

O ensaio de resistência à compressão dos pisos de concreto foi realizado segundo as recomendações da ABNT NBR 9781 [19] aos 28 dias de idade.

Para a sua determinação foi necessário primeiramente tomar as medidas nominais do comprimento, largura e espessura dos pisos de concreto.

Após o processo de cura dos pisos de concreto, estes foram capeados com uma mistura de $75 \%$ de enxofre e $25 \%$ de caulim com a finalidade de regularizar a superfície das extremidades dos mesmos.

Foi utilizada uma prensa hidráulica para ensaios mecânicos com capacidade de 120 toneladas. Os pisos de concreto foram dispostos sobre as placas auxiliares de ensaio, com os eixos verticais coincidentes. No momento do ensaio o carregamento foi feito continuamente, com velocidade de $550 \mathrm{kPa} / \mathrm{s}$, até a ruptura completa dos pisos.

Segundo a norma da ABNT NBR 9781 [19] a resistência à compressão do piso de concreto, expressa em MegaPascals (MPa) é obtida dividindo-se a carga de ruptura, expressa em Newtons (N), pela área de carregamento, expressa em milímetros quadrados $\left(\mathrm{mm}^{2}\right)$, multiplicando-se o resultado pelo fator $\mathrm{p}$, função da altura da peça, conforme Tabela 2 .

Tabela 2: Fator multiplicativo "p" em função da altura da peça.

\begin{tabular}{c|c}
\hline ESPESSURA NOMINAL DA PEÇA (MM) & $\mathbf{p}$ \\
\hline 60 & 0,95 \\
\hline 80 & 1,00 \\
\hline 100 & 1,05 \\
\hline
\end{tabular}

Fonte: ABNT NBR 9781 [19].

Para a determinação da resistência à compressão estimada considera-se as equações 1 e 2 .

$f p k, e s t=f p-t \times s$

Sendo:

$s=\sqrt{\frac{\sum(f p-f p i)^{2}}{n-1}}$ 
onde:

fp - resistência média das peças $(\mathrm{MPa})$;

fpi - resistência individual das peças (MPa);

fpk,est - resistência característica estimada à compressão (MPa);

$\mathrm{n}$ - número de peças da amostra;

$\mathrm{s}$ - desvio padrão da amostra (MPa);

$\mathrm{t}$ - coeficiente de Student (Tabela 3) em função do tamanho da amostra.

Tabela 3: Coeficiente de Student em função do tamanho da amostra.

\begin{tabular}{c|c}
\hline $\boldsymbol{n}$ & $\boldsymbol{t}$ \\
\hline 6 & 0,920 \\
\hline 7 & 0,906 \\
\hline 8 & 0,896 \\
\hline 9 & 0,889 \\
\hline 10 & 0,883 \\
\hline 12 & 0,876 \\
\hline 14 & 0,870 \\
\hline 16 & 0,866 \\
\hline 18 & 0,863 \\
\hline 20 & 0,861 \\
\hline 22 & 0,859 \\
\hline 24 & 0,858 \\
\hline 26 & 0,856 \\
\hline 28 & 0,855 \\
\hline 30 & 0,854 \\
\hline 32 & 0,842 \\
\hline
\end{tabular}

Fonte: ABNT NBR $9781[19]$.

\subsubsection{Determinação da Absorção de Água}

A absorção de água é considerada pela ABNT NBR 9781 [19] como o incremento de massa de um corpo sólido poroso devido à penetração de água em seus poros permeáveis, em relação à sua massa no estado seco.

Neste ensaio foram utilizados 4 corpos de prova retangulares de pisos de concreto de dimensões 200x100x60 mm para cada traço estudado, conforme a ABNT NBR 9781 [19].

Este ensaio foi realizado seguindo os passos:

- Preparação do corpo de prova com a retirada do pó e partículas soltas com auxílio de uma escova;

- Imersão dos corpos de prova em água à temperatura de $23^{\circ} \mathrm{C}$, por $24 \mathrm{~h}$; $\mathrm{m} 2$

- Pesagem do corpo de prova na condição saturada com superfície seca, anotando-se sua massa saturada

- Colocação dos corpos de prova saturados na estufa a temperatura de $110^{\circ} \mathrm{C}$, por $24 \mathrm{~h}$;

- Pesagem do corpo de prova na condição seco em estufa, anotando-se sua massa seca ml;

O valor da absorção de água de cada corpo de prova foi calculado pela equação 3 .

$A=\frac{m 2-m 1}{m 1} \times 100$

onde: 
A - absorção de cada corpo de prova (\%);

$\mathrm{m} 1$ - massa do corpo de prova seco $(\mathrm{g})$;

$\mathrm{m} 2$ - massa do corpo de prova saturado $(\mathrm{g})$.

\subsubsection{Análise da microestrutura do concreto}

A análise da microestrutura do concreto foi realizada pelas imagens de elétrons secundários com ênfase em aspectos morfológicos das amostras de concreto obtidas por meio do microscópio eletrônico de varredura. As amostras ensaiadas foram extraídas de corpos de prova de concreto ensaiados à compressão aos 28 dias. Estas foram devidamente preparadas aplicando-se uma fina camada de carbono sobre as mesmas, pelo processo de metalização.

As amostras de concreto foram analisadas por meio do Microscópio Eletrônico de Varredura (MEV) LEO 430i, acoplado a um espectrômetro de energia dispersiva (EDS) para análises semi-quantitativas e um detector de catodoluminescência (Chroma CL), além do aquisitor de dados. As condições de operação foram: energia do feixe de elétrons: $20 \mathrm{kV}$, corrente do feixe: entre 500 pA (imagens) e 6000 pA (microanálise) e distância de trabalho: $19 \mathrm{~mm}$.

\section{RESULTADOS}

\subsection{Massa específica e teor de ar pelo método gravimétrico.}

Os ensaios de massa específica aparente e teor de ar foram realizados no estado fresco do concreto e os resultados são apresentados na Tabela 4.

Tabela 4: Determinação da massa específica aparente, consumo de cimento e teor de ar.

\begin{tabular}{c|c|c|c|c}
\hline TRAÇOS & $\begin{array}{c}\text { MASSA ESPECÍFICA } \\
\text { APARENTE } \\
\left(\mathbf{k g} / \mathbf{m}^{\mathbf{3}}\right)\end{array}$ & $\begin{array}{c}\text { REDUÇÃO DA MASSA ES- } \\
\text { PECÍFICA EM RELAÇÃO A } \\
\text { T0 (\%) }\end{array}$ & $\begin{array}{c}\text { CONSUMO DE } \\
\text { CIMENTO } \\
\left(\mathbf{k g} / \mathbf{m}^{\mathbf{3}}\right)\end{array}$ & $\begin{array}{c}\text { TEOR DE AR } \\
\mathbf{( \% )}\end{array}$ \\
\hline T 0 & 2498 & 0 & 438 & 0,4 \\
\hline T 2,5 & 2449 & $-1,96$ & 425 & 0,6 \\
\hline T 5 & 2437 & $-2,43$ & 424 & 0,9 \\
\hline T 10 & 2380 & $-4,71$ & 416 & 2,9 \\
\hline T 20 & 2364 & $-5,33$ & 417 & 2,8 \\
\hline T 30 & 2360 & $-5,49$ & 419 & 2,2 \\
\hline
\end{tabular}

Verifica-se na Tabela 4, uma tendência de diminuição da massa específica para os traços com teores crescentes de borracha. Na Figura 1 está indicado a redução da massa específica dos pisos de concreto com borracha em relação ao traço de referência (sem borracha).

Observa-se, segundo Tabela 4, a tendência do aumento do teor de ar incorporado nas misturas com borracha.

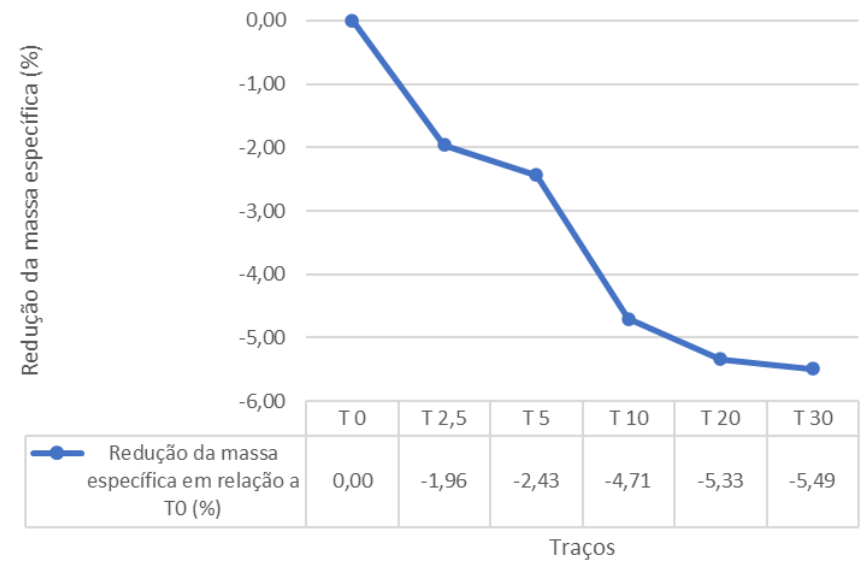


Figura 1: Redução da massa específica dos pisos de concreto com borracha em relação ao traço de referência (sem borracha).

SILVA et al. [15] em sua pesquisa, ao ensaiar piso tátil intertravado de concreto contendo até $50 \%$ de borracha em substituição à massa da areia, também verificou resultados similares. PELISSER et al. [14] observaram para os traços, em massa, 1:3,5 (cimento: agregados) e 1:5 a densidade do concreto com 10\% de borracha reciclada em substituição a areia foi reduzida em $13 \%$ em relação ao concreto de referência. Murugan e Chidambarathanu [31] também verificaram diminuição da densidade de pisos de concreto com até $25 \%$ de borracha em substituição ao volume de areia.

As imagens de microscopia, Figuras 4 a 10 apresentam aumento do número de vazios na pasta devido ao aumento da incorporação de ar. Bem como, um aumento da zona de transição, evidenciando uma estrutura da pasta menos densa conforme o aumento do teor de borracha, justificando a redução da resistência à compressão.

\subsection{Absorção de água dos pisos intertravados de concreto}

Os resultados de absorção de água dos pisos de concreto, aos 28 dias de idade (Figura 2) ficaram abaixo de $6 \%$ atendendo o limite máximo especificado pela ABNT NBR 9781 [19]. Na Tabela 5 estão os resultados obtidos neste ensaio.

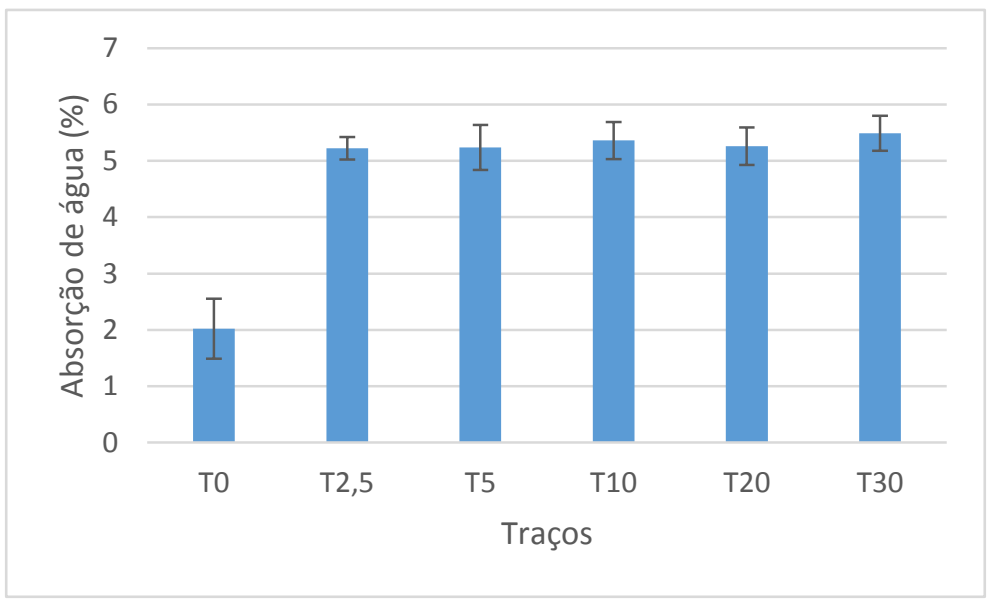

Figura 2: Valores médios para a absorção de água dos pisos de concreto.

Tabela 5: Resultados dos ensaios de absorção de água dos pisos de concreto, aos 28 dias.

\begin{tabular}{l|c|c|c|c}
\hline \multirow{2}{*}{ TRAÇOS } & \multicolumn{4}{|c}{ ABSORÇÃO DE ÁGUA (\%) } \\
\cline { 2 - 5 } & MÉDIA & DESVIO PADRÃO & VARIÂNCIA & COEFICIENTE DE VARIAÇÃO (\%) \\
\hline T0 & 2,02 & 0,53 & 0,28 & 26,15 \\
\hline $\mathrm{T} 2,5$ & 5,22 & 0,20 & 0,04 & 3,87 \\
\hline $\mathrm{T} 5$ & 5,24 & 0,40 & 0,16 & 7,68 \\
\hline $\mathrm{T} 10$ & 5,36 & 0,33 & 0,11 & 6,17 \\
\hline $\mathrm{T} 20$ & 5,26 & 0,33 & 0,11 & 6,26 \\
\hline $\mathrm{T} 30$ & 5,49 & 0,31 & 0,09 & 5,60 \\
\hline
\end{tabular}

Os resultados de absorção de água dos pisos intertravados de concreto demonstram que a substituição de parte da areia pelos resíduos de borracha nos concretos aumenta a absorção de água e a tendência a diminuição da resistência à compressão. As análises microestruturais apresentadas nas Figuras 4 a 10 auxiliam no entendimento destes resultados. 
A borracha incorpora ar na mistura, e esse comportamento pode ser observado na microestrutura do concreto, nas imagens obtidas por meio do MEV. Isto explica os resultados do ensaio de absorção de água, onde os traços com borracha T2,5, T5, T10, T20, T30 apresentaram maiores taxas de absorção de água comparando-se ao traço T0 (sem borracha). Entretanto, como pode ser observado na Figura 2, que todos os resultados obtidos atenderam a norma brasileira ABNT NBR 9781 [19] para todas as composições de concreto estudadas, chegando perto dos $6 \%$ a medida que se aumentava o teor borracha nos traços.

Os valores inferiores a $6 \%$ também foram constatados no trabalho de SILVA et al. [15] para todos os traços dos pisos intertravados de concreto com borracha.

Nos estudos de SILVA et al. [32] concretos de alto desempenho contendo 7,5\%, $15 \%$ e $30 \%$ de borracha em relação à massa da areia apresentaram valores de absorção de água de $82,35 \%, 74,38 \%, 71,17 \%$ maiores que o traço de referência $(1,53 \%)$, respectivamente.

\subsection{Resistência característica à compressão}

A resistência característica à compressão é um parâmetro importante na avaliação do desempenho do piso intertravado de concreto. A Norma Brasileira ABNT NBR 9781 [19] prescreve uma resistência característica à compressão igual ou superior a $35 \mathrm{MPa}$ para tráfego de veículos leves e $50 \mathrm{MPa}$ para tráfego de veículos pesados.

Os valores de resistência característica estimada à compressão (fpk,est) dos pisos de concreto de dimensões 200x100x60 mm, aos 28 dias de idade, são apresentados na Figura 3.

Na Tabela 6 estão os resultados da análise estatística dos resultados individuais de resistência à compressão dos pisos ensaiados, considerando a resistência média das peças, o desvio padrão, a variância e o coeficiente de variação.

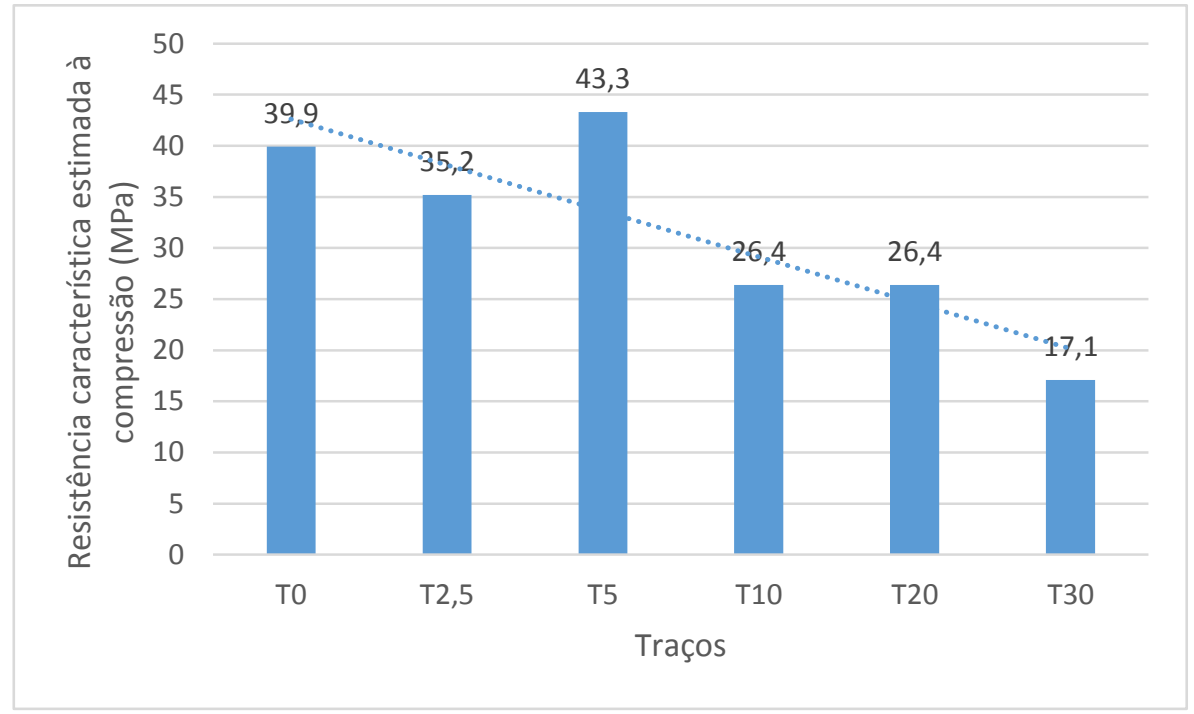

Figura 3: Resistência característica estimada à compressão (fpk,est) dos pisos de concreto.

Tabela 6: Análise estatística dos resultados de resistência à compressão dos pisos ensaiados aos 28 dias.

\begin{tabular}{c|c|c|c|c}
\hline \multirow{2}{*}{ TRAÇOS } & \multicolumn{4}{|c}{ RESISTÊNCIA À COMPRESSÃO (MPa) } \\
\cline { 2 - 5 } & MÉDIA & DESVIO PADRÃO & VARIÂNCIA & COEFICIENTE DE VARIAÇÃO (\%) \\
\hline T0 & 41,50 & 1,79 & 3,20 & 4,31 \\
\hline T2,5 & 36,63 & 1,58 & 2,48 & 4,30 \\
\hline T5 & 44,62 & 1,53 & 2,35 & 3,44 \\
\hline T10 & 28,13 & 1,84 & 3,37 & 6,53 \\
\hline T20 & 30,55 & 4,52 & 20,42 & 14,79 \\
\hline T30 & 23,35 & 6,86 & 47,06 & 29,38 \\
\hline
\end{tabular}


Observando-se os valores referentes aos coeficientes de variação, que mede a extensão da variabilidade dos resultados em relação à média, verifica-se que, aos 28 dias, para os traços com até $20 \%$ de borracha os valores de coeficientes de variação estão entre 3\% a 15\% indicando consistência dos resultados. Para o teor de $30 \%$ de borracha na mistura nota-se aumento do coeficiente de variação, mostrando grande desvio relativo à média apresentando maior variabilidade do resultado.

O ensaio de resistência característica estimada à compressão dos pisos, realizados aos 28 dias de idade, Figura 3, evidencia a tendência da diminuição desta propriedade com teores crescentes de resíduos de borracha na mistura. Isto pode ser justificado pelo aumento da zona de transição e pela estrutura da pasta menos densa dos concretos, conforme ocorre o aumento do teor de borracha na mistura, observadas nas imagens das Figuras 4 a 10.

Os traços de concreto com $2,5 \%$ e $5 \%$ de resíduos de borracha atenderam satisfatoriamente os requisitos para tráfego de veículos leves segundo as especificações da ABNT NBR 9781 [19].

Para o traço com 5\% de resíduos de borracha ocorreu um aumento de 8,52\% da resistência característica estimada à compressão (fpk,est) em relação ao traço de referência, justificado pelas análises da microestrutura do material, ou seja, este traço apresenta baixa quantidade de poros na pasta de cimento e completo envolvimento da borracha pelos produtos hidratados da pasta de cimento.

Para os demais traços de concreto com 10\%, $20 \%$ e $30 \%$ de resíduos de borracha verificou-se redução da resistência característica estimada à compressão (fpk,est) comparando-se com o traço de referência de $33,83 \%, 33,83 \%, 57,14 \%$, aos 28 dias, respectivamente. Esta redução de resistência pode ser justificada pelas imagens das Figuras 8, 9 e 10, onde verificou-se a presença de poros de vários tamanhos e microfissuras na pasta.

De acordo com SHEN et al. [33], um fator determinante para o aumento da resistência à compressão do concreto é o nível ótimo de substituição de agregado natural por resíduo de borracha. Quando o teor de borracha é adequado para se distribuir homogeneamente por toda a matriz, a força de carregamento se distribui uniformemente resultando em aumento da resistência à compressão, por outro lado, quando o valor de substituição for acima do nível ótimo, pelo fato da borracha possuir baixo módulo de elasticidade, haverá alguns pontos fracos no concreto, tornando a matriz mais porosa e mais fraca resultando novamente na queda da resistência.

Este comportamento também foi verificado nos estudos de SHEN et al. [33], PACHECO-TORRES et al. [34], YUNG et al. [35]. Parece existir um teor de substituição de parte do agregado miúdo pelo resíduo de borracha que resulta em um empacotamento ótimo das partículas, com aumento da resistência à compressão (LING [3]). Segundo SILVA et al. [5] esta porcentagem parece estar entre 5\% e 10\% de resíduos de borracha.

Pela análise dos resultados obtidos nos ensaios de resistência à compressão e absorção de água realizados nos pisos de concreto pigmentado intertravados, verifica-se que a incorporação de resíduos de borracha é uma opção de reciclagem sustentável e tecnicamente viável. Adicionando a estes resultados, LING [3] observou que os pisos com borracha aumentam a ductilidade do concreto pois, são capazes de absorver maiores quantidades de energia, bem como, SILVA et al. [15] concluíram que a borracha de pneu melhora significativamente a resistência à abrasão do concreto.

\subsection{Microestrutura do concreto}

$\mathrm{Na}$ análise da microestrutura do concreto pode-se visualizar nas imagens de MEV do concreto sem borracha (T0), uma estrutura densa e compacta, porém, com formação heterogênea (Figura 4).

Outros pesquisadores também verificaram esta mesma microestrutura para o concreto sem borracha. ZHU et al. [36] notaram que, para o concreto de alto desempenho sem borracha, a microestrutura do material é densa. SILVA et al. [15] e ANGELIN et al. [37] também verificaram menor quantidade e tamanho dos poros para concretos sem borracha comparando-os com misturas contendo borracha.

Os produtos de hidratação encontrados são principalmente silicatos de cálcio hidratados (C-S-H) com características de filamentos esponjosos e cristais maciços de hidróxido de cálcio $\left(\mathrm{Ca}(\mathrm{OH})_{2}\right)$ (Figura 5) (SILVA [38]; LOPES [39]; MEHTA e MONTEIRO [40]). 


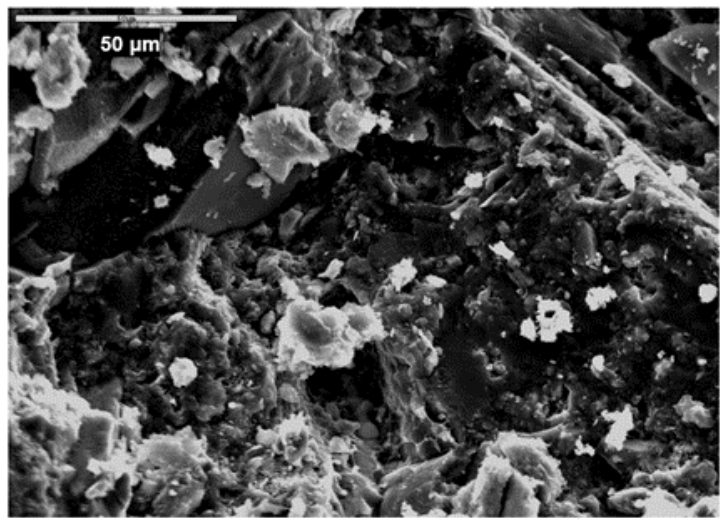

Figura 4: Concreto sem borracha (T0).

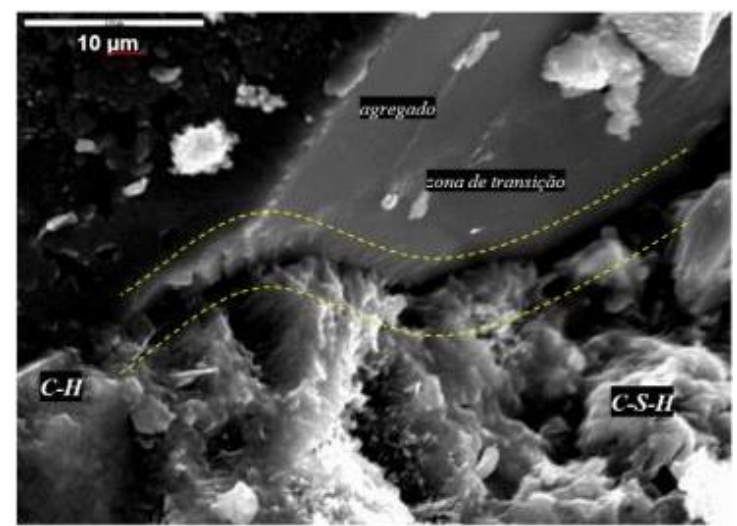

Figura 5: Concreto sem borracha (T0). Presença da zona de transição na interface pasta e agregado.

Para o concreto com 2,5\% de resíduos de borracha observa-se uma estrutura menos compacta e com maior quantidade de vazios pequenos comparando-se com o traço de referência (Figura 6). Observa-se presença marcante de placas maciças de hidróxido de cálcio $\left(\mathrm{Ca}(\mathrm{OH})_{2}\right)$ e cristais de silicatos de cálcio hidratados (C-S-H).

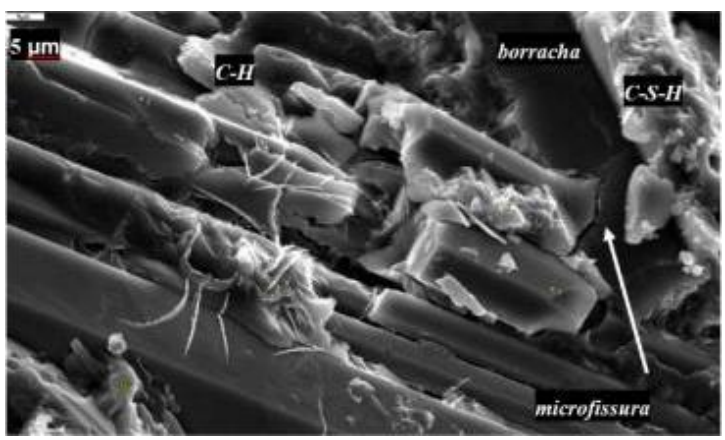

Figura 6: Concreto com 2,5\% de borracha (T2,5). Placas hexagonais de $\mathrm{Ca}(\mathrm{OH})_{2}$ e cristais de silicatos de cálcio hidratados $\mathrm{C}-\mathrm{S}-\mathrm{H}$.

A Figura 7 mostra a microestrutura do concreto com 5\% de substituição da areia pela borracha. Os cristais dos produtos hidratados estão completamente aderidos a borracha e ao agregado, apresentando grande quantidade de silicatos de cálcio hidratados $(\mathrm{C}-\mathrm{S}-\mathrm{H})$ e placas de portlandita $(\mathrm{C}-\mathrm{H})$, resultando em estreita 
zona de transição.

Na Figura 8, para o concreto com 10\% de resíduos de borracha, é possível verificar a presença de poros de vários tamanhos e microfissuras na pasta.

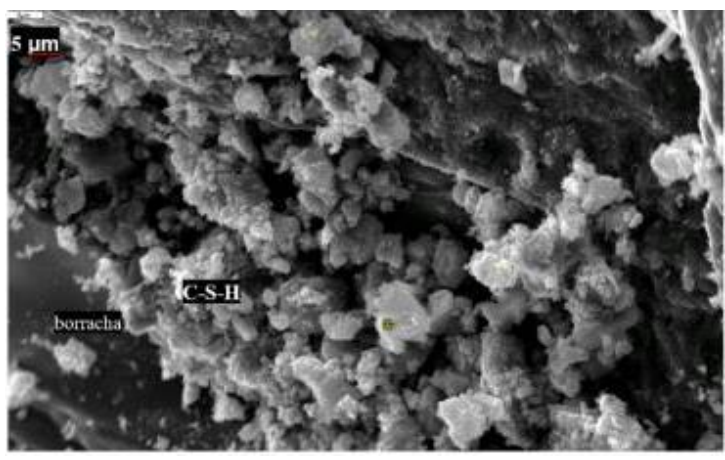

Figura 7: Concreto com 5\% de borracha (T5).

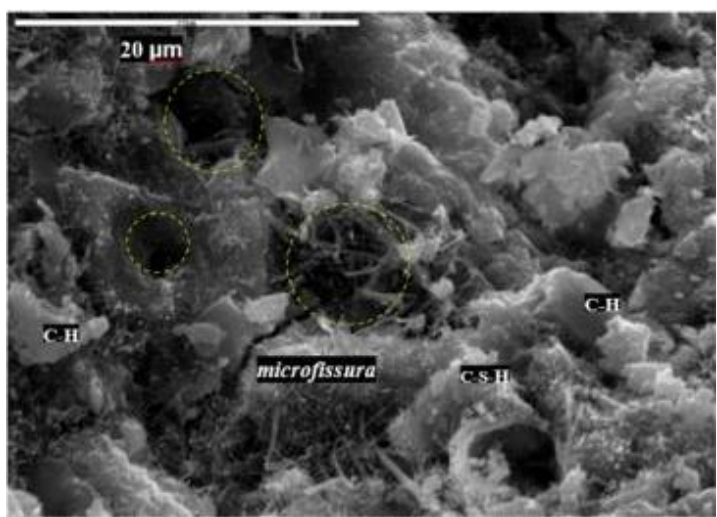

Figura 8: Concreto com 10\% de borracha (T10). Evidência de produtos hidratados C-H e C-S-H, microfissuras e vazios.

O concreto de traço T20, com $20 \%$ de incorporação de borracha, apresenta muitos poros na sua microestrutura e microfissuras na pasta (Figura 9). No traço T30, com 30\% de incorporação de borracha, nota-se a presença de vazios e grandes poros, microfissuras e zona de transição mostrando uma estrutura da pasta menos densa que os demais traços de concreto, justificando a redução da resistência à compressão (Figura 10).

O aumento do número de vazios na pasta de cimento, devido ao aumento do teor de ar nas misturas de concreto com borracha, também foi confirmado por outros pesquisadores (ZHU et al. [36]; WANG et al. [7]).

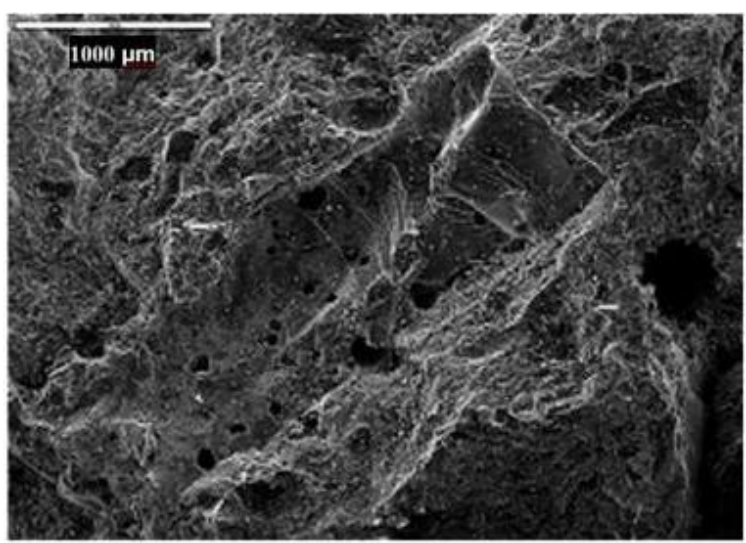


Figura 9: Concreto com 20\% de borracha (T20). Presença de poros na pasta de cimento.

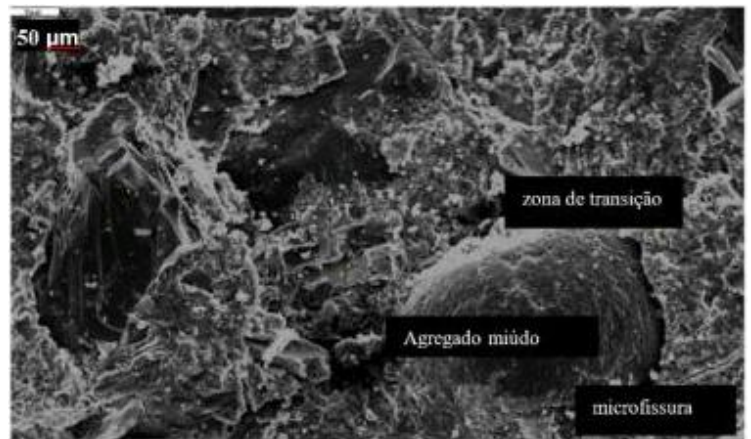

Figura 10: Concreto com 30\% de borracha (T30). Zona de transição acentuada ao redor do agregado e vazios ao redor da borracha.

\section{DISCUSSÃO}

Pela análise dos resultados obtidos nos ensaios realizados para os pisos intertravados de concreto pigmentado verifica-se que a incorporação de resíduos de borracha é uma opção de reciclagem sustentável e tecnicamente viável. O ensaio de resistência à compressão dos pisos, realizado aos 28 dias de idade, mostra que os pisos de concreto contendo os teores de resíduos de borracha de $2,5 \%$ e $5 \%$ podem ser empregados em vias destinadas a tráfego de pedestres, veículos leves e veículos comerciais de linha. Os resultados referentes à análise da microestrutura corroboram com os encontrados na literatura confirmando que, para misturas de concreto sem borracha a pasta de cimento é densa com pequeno volume de vazios (ZHU et al. [36]).

Para o traço de concreto com 5\% de resíduos de borracha (T5), nota-se que, a borracha está completamente envolvida pelos produtos hidratados da pasta de cimento, apresentando baixa quantidade de poros o que resulta em aumento de sua resistência à compressão em comparação aos demais traços. Para as composições de concreto com maiores incorporações de borracha verifica-se:

- aumento do teor de ar na pasta, afetando a densidade da estrutura e aumentando o número de poros grandes na estrutura interna do concreto (ZHU et al. [36]);

- aumento de poros no concreto com o emprego de porcentagens crescentes de borracha na mistura (SILVA et al. [15]);

- pasta de cimento mais porosa ao redor do resíduo de borracha (SILVA et al. [15]; ANGELIN et al. [37]);

- aumento da espessura da zona de transição entre o resíduo de borracha e a pasta de cimento (SIL-

VA et al. [15]; SILVA et al. [32]; TURKI et al. [41]);

- presença de fissuras na zona de transição (SILVA et al. [15]; ANGELIN et al. [42]);

- diferentes vazios esferoidais ou irregulares na pasta de cimento, os quais podem ser facilmente confundidos (ANGELIN et al. [42]);

- maior índice de porosidade (SILVA et al. [32]).

\section{CONCLUSÕES}

A partir deste estudo, que trata de pisos de concreto pigmentado fabricado com cimento Portland branco e resíduos de borracha, pode-se concluir:

Os pisos intertravados de concreto sem borracha e aqueles contendo $2,5 \%$ e $5 \%$ de resíduos de borracha em relação à massa de areia atenderam a normativa brasileira com relação à resistência característica à compressão aos 28 dias. Verifica-se assim a viabilidade técnica do emprego de até $5 \%$ de resíduos de borracha em concretos empregados na produção de pisos intertravados, contendo cimento branco e pigmento de tonalidade azul, destinados a tráfego de pedestres, veículos leves e veículos comerciais de linha, segundo as limita- 
ções da ABNT NBR 9781 [12].

Os pisos intertravados com teores de $10 \%, 20 \%$ e $30 \%$ de resíduos de borracha apresentaram resistências características à compressão inferiores a $35 \mathrm{MPa}$, e podem ser aplicados em sistemas de pavimentação que requerem solicitações leves, de baixa intensidade de sobrecarga, como calçadas, ciclovias, pátios, praças, canteiros centrais, vias locais em condomínios residenciais.

Porém todas as composições de concreto estudadas contendo $0 \%, 2,5 \%, 5 \%, 10 \%, 20 \%$ e $30 \%$ de resíduos de borracha atenderam ao quesito quanto à absorção de água segundo a norma brasileira, apresentando valores inferiores a $6 \%$.

Com relação à análise da microestrutura dos concretos realizada por meio de imagens geradas pelo microscópio eletrônico de varredura (MEV) verifica-se que o concreto de referência (sem borracha) apresenta pasta de cimento densa e compacta. O concreto contendo $5 \%$ de resíduos de borracha, apresenta baixa quantidade de poros na pasta de cimento e completo envolvimento da borracha pelos produtos hidratados da pasta de cimento, justificando a maior resistência à compressão comparando-se com as demais misturas de concreto. Para teores crescentes de borracha no concreto, traços T10, T20, T30, observa-se na análise da microestrutura: incorporação de ar, aumento da porosidade e do número de vazios na pasta de cimento, aparecimento de microfissuras e zona de transição acentuada entre os agregados e a pasta de cimento.

\section{AGRADECIMENTOS}

À equipe técnica do Laboratório de Materiais de Construção da Faculdade de Tecnologia - UNICAMP, pelo auxílio na execução dos ensaios, aos projetos concedidos pela FAPESP (2018/12076-5), (2018/14945-0) e CNPq (309409/2017-9) (311009/2017-4).

O presente trabalho foi realizado com apoio da Coordenação de Aperfeiçoamento de Pessoal de Nível Superior Brasil (CAPES) - Código de Financiamento 001.

\section{BIBLIOGRAFIA}

[1] FIORITI, C.F., INO, A., AKASAKI, J.L., "Análise experimental de blocos intertravados de concreto com adição de resíduos do processo de recauchutagem de pneus", Acta Scientiarum Technology, v.32, n.3, pp. 237-244, Nov. 2010.

[2] JAMSHIDI, A., KURUMISAWA, K., WHITE, G., et al., "State-of-the-art of interlocking concrete block pavement technology in Japan as a post-modern pavement", Construction and Building Materials, v. 200, pp. 713-755, Mar. 2019.

[3] LING, T.C., "Effects of compaction methods and rubber content on the properties of concrete paving blocks", Construction and Building Materials, v. 28, pp. 164-75, Mar. 2012.

[4] SOFI, A., "Effect of waste tyre rubber on mechanical and durability properties of concrete - A review", Ain Shams Engineering Journal, v. 9, pp. 2691-2700, Dec. 2018.

[5] SILVA, F.M., VAZ, V.V., GACHET-BARBOSA, L.A., et al., "Avaliação da resistência mecânica de pisos intertravados de concreto sustentáveis (PICS)", Revista Matéria (Rio de Janeiro), v.22, n.1, e11778, Abr. 2017.

[6] GERGES, N.N., ISSA, C.A., FAWAZ, S.A., "Rubber concrete: mechanical and dynamical properties", Case Studies in Construction Materials, v. 9, e00184, Dec. 2018.

[7] WANG R., GAO, P., TIAN, M., et al., "Experimental study on mechanical and waterproof performance of lightweight foamed concrete mixed with crumb rubber", Construction and Building Materials, v. 209, pp. 655-664, Jun. 2019.

[8] LI, N., LONG, G., MA, C., et al., "Properties of self-compacting concrete (SCC) with recycled tire rubberaggregate: A comprehensive study", Journal of Cleaner Production, v. 236, 117707, Nov. 2019.

[9] BIDECI, A., ÖZTÜRK, H., BIDECI, Ö.S. et al., "Fracture energy and mechanical characteristics of selfcompacting concretes including waste bladder tyre", Construction and Building Materials, v. 149, pp. 669678, Sep. 2017.

[10] ZHENG, L., SHARON, H.X., YUAN, Y., "Strength, modulus of elasticity, and brittleness index of rubberized concrete", 
Journal of Materials in Civil Engineering, v. 20, pp. 692-699, Nov. 2008.

[11] NAJIM, K.B., HALL, M.R., "Mechanical and dynamic properties of self-compacting crumb rubber modified concrete"

Construction and Building Materials, v. 27, pp. 521-530, Feb. 2012.

[12] ABDELALEEM, B.H., ISMAIL, M.K., HASSAN, A.A.A., "The combined effect of crumb rubber and synthetic fibers on impact resistance of self-consolidating concrete", Construction and Building Materials, v. 162, pp. 816-829, Feb. 2018.

[13] SILVA, L.S.; MOUTA, J.R.; COSTA, M.C.B., et al. Concreto com borracha de recauchutagem de pneu para uso em pavimentação de baixo tráfego. Revista Matéria (Rio de Janeiro), v.24, n.2, Jan. 2019.

[14] PELISSER, F., ZAVARISE, N., LONGO, T.A., et al. "Concrete made with recycled tire rubber: effect of alkaline activation and silica fume addition", Journal of Cleaner Production, v. 19, pp. 757-763, Apr. 2011.

[15] SILVA, F.M., GACHET-BARBOSA, L.A., LINTZ, R.C.C., et al. "Investigation on the properties of concrete tactile paving blocks made with recycled tire rubber", Construction and Building Materials, v. 91, pp. 71-79, Aug. 2015.

[16] AGUIAR, C.A., "Concreto de cimento Portland branco estrutural: análise da adição de pigmentos quanto a resistência à compressão", Tese de M.Sc., Universidade Federal do Rio Grande do Sul, Porto Alegre, RS, Brasil, 2006.

[17] LEE, H-S, LEE, J-Y., YU, M-Y., "Influence of iron oxide pigments on the properties of concrete interlocking blocks", Cement and Concrete Research, v. 33, pp. 1889-1896, Jun. 2003.

[18] PIOVESAN, A.Z., "Estudo sobre a influência da adição de pigmentos em propriedades de durabilidade e na cromacidade do concreto de cimento Portland branco", Tese de M.Sc., Universidade Federal do Rio Grande do Sul, Porto Alegre, RS, Brasil, 2009.

[19] ASSOCIAÇÃO BRASILEIRA DE NORMAS TÉCNICAS. NBR 9781 - Peças de concreto para pavimentação - Especificação e métodos de ensaio, Rio de Janeiro (2013).

[20] ASSOCIAÇÃO BRASILEIRA DE NORMAS TÉCNICAS. NBR 16697 - Cimento Portland - Requisitos, Rio de Janeiro (2018).

[21] ASSOCIAÇÃO BRASILEIRA DE NORMAS TÉCNICAS. NBR 23 - Cimento Portland e outros materiais em pó - Determinação da massa específica. Rio de Janeiro (2001).

[22] ASSOCIAÇÃO BRASILEIRA DE NORMAS TÉCNICAS. NBR 11579 - Cimento Portland - Determinação do índice de finura por meio da peneira $75 \mu \mathrm{m}$ ( $\mathrm{n}^{\circ}$ 200). Rio de Janeiro (2012).

[23] ASSOCIAÇÃO BRASILEIRA DE NORMAS TÉCNICAS. NBR NM 52 - Agregado miúdo - Determinação da massa específica e massa específica aparente. Rio de Janeiro, 2009.

[24] ASSOCIAÇÃO BRASILEIRA DE NORMAS TÉCNICAS. NBR NM 45 - Agregados - Determinação da massa unitária e do volume de vazios. Rio de Janeiro, 2006.

[25] ASSOCIAÇÃO BRASILEIRA DE NORMAS TÉCNICAS. NBR NM 30 - Agregado miúdo - Determinação da absorção de água. Rio de Janeiro, 2001.

[26] ASSOCIAÇÃO BRASILEIRA DE NORMAS TÉCNICAS. NBR 248 - Agregados - Determinação da composição granulométrica, Rio de Janeiro, 2003.

[27] ASSOCIAÇÃO BRASILEIRA DE NORMAS TÉCNICAS. NBR NM 53 - Agregado graúdo - Determinação da massa específica, massa específica aparente e absorção de água, Rio de Janeiro, 2009.

[28] FERNANDES, I., Blocos e Pavers - Produção e Controle de Qualidade, 3 ed., São Paulo, Treino Assessoria, 2012.

[29] ASSOCIAÇÃO BRASILEIRA DE NORMAS TÉCNICA. NBR NM 67 - Concreto - Determinação da consistência pelo abatimento do tronco de cone, Rio de Janeiro, 1998.

[30] ASSOCIAÇÃO BRASILEIRA DE NORMAS TÉCNICAS. NBR 9833 - Concreto fresco - Determinação da massa específica, do rendimento e do teor de ar pelo método gravimétrico, Rio de Janeiro (2009).

[31] MURUGAN R. B. M., CHIDAMBARATHANU, N., "Investigation on precast concrete paver block with waste tyre crumb rubber", Road Materials and Pavement Design, v. 17, pp. 1-18, Dec. 2015.

[32] SILVA, F.M., MIRANDA JR, E.J.P., SANTOS, J.M.C., et al. "The use of tire rubber in the production of high-performance concrete", Cerâmica, v. 65, pp. 110-114, Jan. 2019. 
[33] SHEN, W., SHAN, L., ZHANG, T., et al. "Investigation on Polymer-rubber aggregate modified porous concrete", Construction and Building Materials, v.38, pp. 667-674, Jan. 2013.

[34] PACHECO-TORRES, R., CERRO-PRADA, E., ESCOLANO, F., et al. "Fatigue performance of waste rubber concrete for rigid road pavements", Construction and Building Materials, v. 176, pp. 539-548, Jul. 2018.

[35] YUNG, W.H., YUNG, L.C., HUA, L.H., “A study of the durability of waste tire rubber applied to selfcompacting concrete", Construction and Building Materials, v. 41, pp. 665-672, Apr. 2013.

[36] ZHU, H., WANG, Z., XU, J., et al. "Microporous structures and compressive strength of highperformance rubber concrete with internal curing agent", Construction and Building Materials, v. 215, pp. 128-134, Aug. 2019.

[37] ANGELIN, A.F.; MIRANDA, E.J.P.; SANTOS, et al. "Rubberized mortar: The influence of aggregate granulometry in mechanical resistances and acoustic behavior", Construction and Building Materials, v. 200, pp. 248-254, Mar. 2019.

[38] SILVA, B.C.L., "Avaliação de piso intertravado de concreto de cimento portland branco pigmentado com resíduos de borracha”, Tese de M.Sc., UNICAMP, Limeira, SP, Brasil, 2019.

[39] LOPES, T. B., "Comparação da microestrutura do concreto auto adensável com o concreto convencional”, Tese de M.Sc., UNICAMP, Limeira, SP, Brasil, 2016.

[40] MEHTA, P.K.; MONTEIRO, P.J., Concreto: Microestrutura, Propriedades e Materiais, 2 ed. São Paulo, IBRACON, 2014.

[41] Turki, M., Bretagne, E., Rouis, M.J., Quéneudec, M., "Microstructure, physical and mechanical properties of mortar-rubber aggregates mixtures", Construction and Building Materials, v. 23, pp. 2715-2722, July 2009.

[42] ANGELIN, A.F., LINTZ, R.C.C., GACHET-BARBOSA, L.A., et al. "The effects of porosity on mechanical behavior and water absorption of an environmentally friendly cement mortar with recycled rubber", Construction and Building Materials, v. 151, pp. 534-545, Oct. 2017.

\section{ORCID}

Betolvem Cristhian Lucio da Silva Luísa Andréia Gachet Rosa Cristina Cecche Lintz https://orcid.org/0000-0002-4837-4824

https://orcid.org/0000-0002-1661-2605

https://orcid.org/0000-0002-7201-3260 